Annual Review of Applied Linguistics (2002) 22, 263-278. Printed in the USA.

Copyright ${ }^{\circledR} 2002$ Cambridge University Press 0267-1905/01 $\$ 9.50$

\title{
14. DISCOURSE APPROACHES TO WRITING ASSESSMENT
}

\author{
Ulla Connor and Aymérou Mbaye
}

\begin{abstract}
At present, mastery of English for educational and professional purposes contributes significantly to expansion of the role of English as a language of world communication. In this context, the teaching-and, consequently, the assessment-of EFL/ESL writing is receiving more attention than ever before. This chapter argues that, although this renewed interest in the evaluation of writing has resulted in advances in the field of language testing, it has by and large failed to incorporate insights gained from recent developments in text analysis. There is a considerable gap between current practices in writing assessment and criteria suggested by advances in knowledge of discourse structure. We illustrate this gap by contrasting current practices in the scoring of two major EFL/ESL writing tests with knowledge of text characteristics generated from recent developments in text analysis. The review concludes by making the case for bridging the gap and by proposing a model of writing assessment that incorporates both linguistic and discoursal features of texts.
\end{abstract}

With the phenomenal spread of English as global lingua franca, the need for a mastery of this language for educational and/or professional purposes has heightened. EFL and ESL programs that, before, essentially concerned themselves with developing general language proficiency among students, now emphasize the students' development of literacy skills, especially in advanced L2 English classes. As a consequence, writing instruction is now receiving more attention than it probably ever did. Since, in the context of education, testing strives to bridge up the gap between teaching and learning (White, 1985), the resurgence of interest in the teaching of EFL/ESL writing has translated into a resurgence in attention to issues of assessing writing. A testimony to this resurgence is the many publications in the recent past that have visited or revisited the issue of second language writing assessment (Alderson, Clapham, \& Wall, 1995: Bachman \& Palmer; 1996; Cohen, 1994; Cumming, 1998; Hamp-Lyons, 1991; Kroll, 1998; Weir, 1993; Yancey \& Huot, 1997). This added attention has contributed to 
noticeable changes in L2 and L1 writing assessment. For instance, performance testing and a shift from exclusive indirect testing of writing to a combination of direct and indirect testing, or even direct testing of writing altogether, now characterize testing practices in many places which, until recently, lived by totally different practices. This added attention to the testing of writing has also paved the way for more awareness among teachers and EFL/ESL professionals of important testing issues such as validity and reliability of testing instruments test types and purposes, specific methods for assessing writing and other skills, and so forth.

However, in the specific domain of writing assessment, second language testing developments and the changes in practices that have come with it do not seem to go much beyond traditional overreliance on linguistic criteria for evaluating writing. Holistic, primary trait, and portfolio approaches to writing assessment fundamentally offer no breakaway from an evaluation of writing based almost exclusively on linguistic criteria. Analytic and multiple-trait scoring guides, although they offer room for the inclusion of other criteria of writing, in practice hardly venture beyond inclusion of the generic criterion of "organization." Even where the term "rhetorical features of text" is used, it often appears be synonymous with "organization."

This is occurring despite the valuable insights that great advances in text analysis can provide into our understanding of writing ability. This chapter addresses the resulting gap in second language writing assessment. It will first review the development of current practices in the evaluation of writing, and the state of advances in text analysis. After that, it will examine the scoring philosophy of two representative ESL tests to illustrate the discrepancy between the current testing and text analysis theories. It ends with a proposal for a communicative model of writing that incorporates current thinking in linguistic/rhetorical text analysis.

\section{Recent Developments in Second Language Assessment}

"Every [language] test has a theory [of language] behind it" (Alderson, Clapham, \& Wall, 1995, p. 16). This theory consists of beliefs of what language is and of how its mastery is reflected. For a considerable period in the modern history of English language teaching (ELT) there did not seem to be explicit awareness of this relationship between theoretical constructs of language and procedures for testing language, probably because the attention of ELT researchers was focused on such areas as the structures of language and, later, language errors. With the spread of ELT, and with the increased need for learners of the language to use it, not only for reading purposes, but for actual communication with other speakers of English, researchers concluded that language should mainly be taught for communication; communicative competence, along with its prerequisite of linguistic competence, became what EFL/ESL teachers strove to equip their 
linguistic competence, became what EFL/ESL teachers strove to equip their students with. By proposing an insightful framework for the conceptualization of communicative competence, Canale and Swain (1980) provided the grounds for explicitly relating language tests to the construct of language proficiency and communicative competence.

The model of communicative competence developed by Canale and Swain (1980) and Canale (1983) consists of four components. The first, grammatical competence, covers "knowledge of lexical items and of rules of morphology, syntax, sentence-grammar semantics, and phonology" (Canale \& Swain, 1980, p. 29); the second component, discourse competence, covers the ability to combine sentences and to form meaningful stretches of language beyond the sentence level, while sociolinguistic and strategic competencies, the last two components, relate respectively to the sociocultural rules of language and discourse, and to the strategies used to compensate for communication breakdowns. Canale and Swain's model of communicative competence, with some adaptations (Bachman \& Palmer, 1996), constitutes a significant factor in the developments in language assessment in the last two decades of the last century. It not only brought about more integration of skills and/or language areas in testing; with its grounding in communicative teaching of English, it ushered in considerations of authenticity and context in language testing. Moreover, the explicit relationship it allowed between the language test and the construct of language and/or communicative competence paved the way for issues of validity that were to be central in the above mentioned developments in language assessment.

The breakthrough in language testing brought about by Canale and Swain's framework did not occur, however, without creating some challenges in testing. Prior to the communicative competence paradigm, instruments for measuring language ability were mostly characterized by discrete-point testing. These tests, despite questionable construct validity, offered the advantage of being scored easily and objectively. Integrative tests of language, especially direct tests of writing, did not present this advantage. Once the definition of communicative competence permitted a reduction in the potential lack of validity of writing tests, the challenge in writing assessment moved to development of scoring procedures that would not jeopardize gains in construct validity.

The challenge here appears to be acute, for, despite the availability of different scoring procedures that can be applied to L2 writing, they have invariably tended to fall short of covering the multiple components of writing ability. Holistic scoring (White, 1985) assigns a single score to a piece of writing based on its quality. Primary-trait scoring (Lloyd-Jones, 1977) bases allotting of a score on a predetermined characteristic feature of the writing task at hand. Both scoring methods present the shortcoming that they allow very limited coverage of the multiple facets of writing ability. A piece of writing in academic contexts may 
present undisputed clarity without satisfying the criterion of expected length. Likewise, if in a piece of writing to be scored, grammatical accuracy is determined as the primary trait, this piece may receive a good or bad score irrespective of the quality of content. By making possible the determination of subscores or overall scores based on specific features of writing, analytic and multiple-trait scoring schemes seemed to indicate that they would be able to achieve in scoring what holistic and primary-trait guides could not. In practice, however, analytic and multiple-trait scales supported few advances. When they covered rhetorical features of writing, these tended to be broad in nature, and thus prevented the evaluation of writing tasks on the basis of the components of writing the most relevant to the specific purpose of the writing task. An illustration of this claim is to be found in the fact that, too often, a persuasive essay would be evaluated on the basis of the presence of an introduction, body, and conclusion. This evaluation may even go as far as judging whether the piece of writing shows, at the paragraph level, identifiable topic sentences and supporting details. However, it is not the mere presence of an identifiable topic statement and supporting details that ensure the persuasiveness of an essay, let alone adherence to an introduction-bodyconclusion structure.

Despite progress in second language writing assessment, then, the scoring of writing seems to present some significant challenges. This paper argues that the solution to these challenges in EFL/ESL writing assessment may come from due attention to developments in text analysis.

\section{Recent Developments in Text Analysis}

In the previous section, we indicated the usefulness of Canale and Swain's model for language testing. This usefulness is not limited to the testing of spoken language; their research has strong implications for the field of discourse and text analysis and the testing of writing. It provides a convenient framework for categorizing components of spoken and written discourse.

For a communicative competence model of writing, we argue that all four competencies included in the Canale and Swain model are needed. These competencies should be reflected in the scoring criteria for writing tests. Naturally, grammatical competence is required in writing instruction and assessment. In addition, mastery of discourse, sociolinguistic, and strategic competencies should also be tested. However, we maintain that in current writing assessment, competencies beyond the basic language and writing proficiencies are not tested.

Canale and Swain's model of communicative competence was primarily developed for the purposes of spoken language analysis and teaching. For written communicative competence, mastery of each component needs to reflect the 
grammatical competence for writing, one must show mastery of spelling and punctuation in addition to mastery of words and structures. To show discourse competence, one must demonstrate knowledge of the discourse organization of genre in addition to cohesion and coherence. To indicate sociolinguistic competence in writing, we consider important such characteristics as written genre appropriacy, audience awareness and appeals to audience, pertinence of claim, and tone. In assessing writing, Canale and Swain's fourth component, strategic competence, will be considered to deal with such interpersonal factors between the reader and writer such as transitions and other metatextual markers, because metatext in writing serves a similar function as do repair strategies in spoken discourse.

The next sections survey empirical research studies that have applied linguistic and rhetorical theories to essay analysis; each study used current theories of texts and text comprehension and operationalized the theoretical concepts for empirical verification of holistic writing quality. We will discuss selected empirical studies that contribute to the understanding related to the mastery of what might be called sociolinguistic aspects of writing, followed by a review of studies concerning discourse competence in writing, and, finally, studies of strategic competence in writing. Grammatical competence in writing is not a concern of this chapter because it deals with within-sentence relations.

\section{Studies of Sociolinguistic Competence}

Sociolinguistic aspects of writing deal with the writer's awareness of the audience and purpose of writing. Text analytical studies related to persuasive appeals and strength of claims with impact on writing assessment will be described in this section. In research on persuasive essay writing, Connor and Lauer (1988) produced a linguistic/rhetorical system to describe and evaluate persuasive student writing. Relying on theories of classical rhetoric and Aristotle's notions of audience and appeals, Connor and Lauer show how the teaching of argumentation in England and the U.S. had replaced the teaching of persuasion in the 19th and 20th centuries. A four-component model of discourse was used: description, narration, argumentation, and exposition. According to Connor and Lauer, the neglect of persuasion continued until Kinneavy's (1971) classification, which again distinguished persuasion from exposition. Kinneavy included persuasion in his classification as one of the four major aims of communication: referential, persuasive, literary, and expressive. As major features of persuasion, Kinneavy distinguished rational, ethical, and emotional appeals as different strategies. These three appeals were adapted for composition research by Connor and Lauer, who developed a scale and rubrics for evaluating the quality of persuasive appeals in student essays, shown in Table 1. 
Table 1

Scoring Scale for Persuasive Appeals

Rational Appeal *

0 No use of the rational appeal

1 Use of some rational appeals, minimally developed, or use of some inappropriate (in terms of major point) rational appeals

2 Use of a single rational appeal or a series of rational appeals with at least two points of development

3 Exceptionally well developed and appropriate single extended rational appeal or a coherent set of rational appeals

Credibility Appeal

0 No use of credibility appeals

1 No writer credibility but some awareness of audience's values, or some writer credibility (other than general knowledge) but no awareness of audience's values

2 Some writer credibility (other than general knowledge) and some awareness of audience's values

3 Strong writer credibility (personal experience) and sensitivity to audience's values (specific audience for the solution)

Affective Appeal

0 No use of affective appeal

1 Minimal use of concreteness of charged language

2 Adequate use of either picture, charged language, or metaphor to evoke emotion

3 Strong use of either vivid picture, charged language, or metaphor to evoke emotion

*Rational appeals were categorized as (quasi-logical, realistic structure, example, and analogy).

In empirical research on student persuasive writing using a large data set from the international writing study (Purves, 1988), Connor and Lauer also adopted another rhetorical model of persuasion for the analysis of student 
persuasive essays, namely, the Toulmin model of argumentative writing (1958). Toulmin (1958) designed his theory of argumentation to justify statements of argument. In the model, the first step is to express an opinion, called "claim." The second feature is the "data," designed to support the claim and to counter any possible challenge to the claim in the form of experience, facts, statistics, or occurrences. The third feature, the "warrant," shows the relation of claim and data. Connor and Lauer operationalized Toulmin's model for a quantifiable, reliable analysis in order to evaluate the level of argumentative strength of the essays. In a series of studies, Connor and Lauer found that Toulmin's model was a powerful predictor of writing quality in the international study of L1 writing in English of students from the U.S., England, and New Zealand. Table 2 includes the Toulmin scale with criteria developed by Connor and Lauer.

Table 2

Criteria for Judging the Quality of Claim, Data, and Warrant

Claim

1 No specific problem stated and/or no consistent point of view. May have one subclaim. No solution offered, or if offered, nonfeasible, unoriginal, and inconsistent with claim.

2 Specific, explicitly stated problem. Somewhat consistent point of view. Relevant to the task. Has two or more subclaims that have been developed. Solution offered with some feasibility with major claim.

3 Specific, explicitly stated problem with consistent point of view. Several well-developed subclaims, explicitly tied to the major claim. Highly relevant to the task. Solution offered that is feasible, original, and consistent with major claim.

Data

1 Minimal use of data. Data of the "everyone knows" type, with little reliance on personal experience or authority. Not directly related to major claim.

2 Some use of data with reliance on personal experience or authority. Some variety in use of data. Data generally related to major claim.

3 Extensive use of specific, well-developed data of a variety of types. Data explicitly connected to major claim. 
Table 2

Criteria for Judging the Quality of Claim, Data, and Warrant (continued)

Warrant

1 Minimal use of warrants. Warrants only minimally reliable and relevant to the case. Warrants may inlcude logical fallacies.

2 Some use of warrants. Though warrants allow the writer to make the bridge between data and claim, some distortion and informal fallacies are evident.

3 Extensive use of warrants. Reliable and trustworthy allowing rater to accept the bridge from data to claim. Highly relevant. Evidence of some backing.

In a smaller-scale L2 study of writing with 22 ESL essays, Connor (1991) correlated scores on the Test of Written English (TWE) of the essays with scores on the Toulmin scale. The correlation between the claim and holistic scores was high $(r=.72)$. In other words, 52 percent of the variation in the holistic scores could be explained by the score for claim. The correlation between the claim and holistic score was even higher than the correlation between the essay length and the holistic score, often a good predictor. The finding suggests that a feature related to persuasiveness was related to raters' holistic quality assessment even though the TWE Scoring Guidelines do not explicitly mention criteria related to the development of a reasonable argument. The criterion closest to this in the TWE Guidelines is "addressing the writing task," which does not appear at TWE levels 3,2 , and 1 . It is worth noting that the average holistic score in the sample study was 2.25; Connor suggested that the TWE Scoring Guidelines might not reflect the kind of communicative competence that research on linguistic/rhetorical features of student essays has found important. It was also recommended that writers and interpreters of tests consult this kind of rhetorical/textlinguistic research for the purposes of test construction. The study implies the need for a revised set of rubrics that will include criteria related to persuasion and level of argument development.

\section{$\underline{\text { Studies of Discourse Competence }}$}

Analyses of written discourse related to the discourse competence category in Canale and Swain's model have been plentiful. They can be organized under three categories: studies of cohesion, studies of coherence, and studies of discourse structure. Detailed discussions of these studies are included in Connor (1990) and Connor (1996). A brief summary of studies with the greatest applicability to writing assessment follows. 
A textlinguistic measure of coherence, topical structure analysis, has been used to explain differences among student essays rated high and low. Topical structure analysis measures the semantic unity of a text by analyzing the relationships of sentence topics to the overall discourse topic. In an ESL context, Schneider and Connor (1991) used a sample of essays written for the Test of Written English and found that topical structure analysis correlated well with readers' judgment of writing quality. Topical structure analysis has been recommended as a tool for student writers to check coherence of their own writing. It could also be used as a method to train raters of student essays to evaluate coherence accurately and explicitly.

Other written discourse analyses also have strong potential for making the assessment of essays more valid because they provide explicit textual markers for raters. Studies of superstructures or global text structures can be powerful measures of essay quality. Several top-level discourse structure theories have been advanced in the past decade, including macrostructures of expository and argumentative essays as well as story structures of narratives. Thus, theories of superstructures have been developed for different types of texts such as exposition, argumentation, and narration, and have been applied to student writing for the purpose of evaluating and describing quality. For example, in order to evaluate students' narratives or teach students to write well-formed stories, Martin and Rothery's story grammar analysis (1986) has been found to be effective. Connor (1996) suggests that the role of superstructures in writing analysis is just beginning, and applications of well-known discourse theories of global text structures have been relatively few. The role of superstructure analysis is likely to grow if and when linguists and teachers of writing increase the focus on other genres in addition to the expository essay, the most commonly taught text genre of student writing.

\section{Studies of Strategic Competence}

A promising theory of the interpersonal dimension in writing is the theory about the metadiscourse of texts. Metatext refers to the nonpropositional information in the text and allows the writer either to organize what is said or express personal feelings and attitudes and interact with the reader. Vande Kopple (1985) was the first to propose a valid and reliable system to describe and evaluate student texts for their metatextual content. In Vande Kopple's system, there are two categories of metatextual markers: textual and interpersonal. Textual markers include text connectives that help readers recognize how texts are organized (e.g., first, next); code glosses help readers grasp the meanings of words; illocution markers make explicit what speech act is being performed (e.g., to sum up, to give an example); and narrators, which let readers know who said or wrote something. Interpersonal metadiscourse includes validity markers, which assess the truth value of propositions, indicate the attitude of the writer, or include commentaries 
directed at the reader. An analysis of metadiscourse in student essays in a crosscultural study involving Finnish and American essays (Crismore, Markkonen, \& Steffensen, 1993), provides careful guidance for others wishing to apply the theory to student data. The system developed by Vande Kopple for L1 purposes and further refined by Crismore et al. for L2 purposes is a useful tool for describing and evaluating the strategic competence in ESL student writing.

\section{Examples From Two EFL Writing Tests}

The Test of Written English (TWE) is a holistically rated test; the essays are scored for overall effectiveness of the communication. The holistic scoring guide has six levels and includes syntactic and rhetorical criteria. For example, an essay in the highest category, according to the Test of Written English (TWE) Scoring Guidelines (Educational Testing Service, 1989):

- $\quad$ Effectively addresses the writing task

- Is well organized and well developed

- Uses clearly appropriate details to support a thesis or illustrate ideas

- Displays consistent facility in the use of language

- Demonstrates syntactic variety and appropriate word choice

Several researchers have questioned the use of holistically rated direct assessment because little is known about what factors influence the scores students receive (Hamp-Lyons, 1991). A think-aloud study of TWE writers' and raters' interpretation of the rating criteria and interpretation of the task was conducted by Connor and Carrell (1993). The results of the study showed neither the writers nor the raters considered the specific requirements of the task (i.e., addressing the rhetorical requirements of the writing task) important. Instead, fluency of language, infrequency of language errors, and development of ideas were consistently mentioned by both groups. Neither did a content analysis reveal a consistent addressing of the task as it was specified in the prompt.

An examination of the scoring guidelines reveals that "addressing the task" appears in the scoring guide as a criterion at the higher levels $(6,5,4)$ but is not mentioned as a criterion for levels 3,2 , and 1 . In other words, one could conclude that the rhetorical context is not important at lower levels of writing. Instead, only language proficiency is considered at these levels.

The ESL Composition Profile (Jacobs, Zingraf, Wormuth, Hartfiel, \& Hughey, 1981) employs an analytic scale rather than a holistic scale to assess ESL writing. In analytic rating, a separate score is assigned for various aspects of writing (e.g., content, organization, vocabulary, language use, and mechanics) unlike holistic rating where only one score is given for each essay. In the ESL 
Composition Profile, the "content" category addresses quality of content with such criteria as development of thesis and relevance to topic. No criteria in the scale apply to the effectiveness of addressing the audience and appeals used.

The scoring rubrics for these two tests-the Test of Written English Guidelines and the ESL Composition Profile-are no doubt useful for the purpose of assessing language proficiency required for general writing skills of heterogeneous ESL writers. Yet, they do not consider constraints specific to writing related to a given purpose.

\section{Conclusion}

In this chapter, we have argued for the inclusion of rhetorical and communicative aspects of writing in the assessment of student writing. We have shown that commonly used tests tend to focus on linguistic aspects of texts (i.e., grammar and vocabulary, and discourse organization). They neglect, however, to consider such important aspects of writing effectiveness as strength of argument and appeals to the audience.

An analogy can be drawn with the communicative competence model of language (Canale \& Swain, 1980), which includes strategic and sociolinguistic competence in addition to grammatical and discourse competence. In Table 3 , we propose a communicative model that is more appropriate for writing instruction and assessment. Components appropriate for writing are listed corresponding to Canale and Swain's four categories.

Table 3

Proposed Writing Competence Model

Communicative Competence Model

(Canale \& Swain, 1980)

Grammatical Competence

Discourse Competence

Sociolinguistic Competence

Strategic Competence
Criteria for Writing Competence Model

Grammar, Vocabulary, Spelling, Punctuation

Discourse Organization, Cohesion, Coherence

Written Genre Appropriacy, Register, Tone

Audience/Reader awareness, Appeals, Pertinence of Claims, Warrants 
We indicated earlier that linguistic competence was not the sole concern. According to our model, a greater emphasis in writing assessment needs to be placed on the masteries of discourse, sociolinguistic, and strategic competence. At the level of discourse competence, emphases should go beyond the structure of text and paragraph to cohesion and coherence. In terms of sociolinguistic competence, the focus should include written awareness of written genre appropriacy, tone, and register of text. Finally, in relation to strategic competence, issues of audience or reader awareness, appeals to the audience, and pertinence of claims are important.

\section{ANNOTATED BIBLIOGRAPHY}

Allaei Kurtz, S., \& Connor, U. (1991). Using performative assessment instruments with ESL student writers. In L. Hamp-Lyons (Ed.), Assessing second language writing in academic contexts (pp. 227-240). Norwood, NJ: Ablex.

The chapter describes a new kind of writing assessment, performative assessment, for use with ESL students. Performative assessment is designed to describe students' writing performance in relation to specific tasks and discourse demands, unlike most ESL writing assessment that has been concerned with general proficiency in writing. Performative assessment is criterion-referenced rather than norm-referenced; students are not compared with each other but are judged according to how well the fulfill the expectations of a particular writing task. The chapter shows a step-wise method for constructing performative assessment assignments. It provides two actual writing tasks and corresponding rubrics to score the writing. Performative assessment tools focus on content and meaning, ignoring sentence structure and the mechanics of writing. Therefore, its positive feature is that it makes instructors and raters more aware of students' ability to respond to the demands of a particular writing task. Besides its potential as an diagnostic tool, performative assessment can also be used in classroom instruction.

Cohen, A. D. (1994). Assessing language ability in the classroom (2nd ed.). Boston, MA: Heinle \& Heinle.

This book covers issues of language assessment in an extensive and up-todate manner. The book starts out with placing language testing within the larger framework of teaching and learning, and then goes on to deal with the construction of language assessment instruments successively before discussing the testing of the four traditional language skills. The section 
on assessing writing goes beyond the construction of prompts to present and evaluate some of the main approaches to scoring writing. Because of the range and breadth of language testing issues covered, this is a most useful book.

Connor, U. (1991). Linguistic/rhetorical measures for evaluating ESL writing. In L. Hamp-Lyons (Ed.), Assessing second language writing in academic contexts (pp. 215-226). Norwood, NJ: Ablex.

The chapter describes a project in which the author developed an analytic system for evaluating students' writing. The system, based on Toulmin's (1958) model of argument, was used to analyze the holistic scoring of TWE essays completed by ESL students. Results indicate that the rhetorical writing measures of the model are a better predictor of essay quality than the previously accepted factor of fluency. The paper consequently advocates more incorporation of textual features in scoring guides for writing.

Connor, U., \& Carrell, P. (1993). The interpretation of tasks by writers and readers in holistically rated direct assessment of writing. In J. G. Carson \& I. Leki (Eds.), Reading in the composition classroom: Second language perspectives (pp. 141-160). Boston, MA: Heinle \& Heinle.

Through protocol analysis, the study reported in this chapter examines the similarities and differences in writers and raters' perception of the importance of content, organization, and language in ESL essays. The study also seeks to determine how writers and raters conceptualized and interpreted the writing task, and whether they were aware of each others' role. Results indicated that both writers and raters highlight language use, content, and development of ideas. Little concern seems to be devoted by both writers and raters to organization, full compliance with the instructions of the prompt, and to considering the perspective of the writer or rater while rating or writing. The authors consider some implications of these findings for ESL writing.

Cumming, A. (1998). Theoretical perspectives on writing. Annual Review of Applied Linguistics, 18, 61-78.

This article presents a theory of second language writing that considers the diverse situations where people produce, learn, teach, and assess second language writing. The article reviews empirical studies that have analyzed the demands for writing that students of a second language encounter; discusses research that examines second language writing instruction; and, most importantly for the current topic, argues for text analyses of student 
writing for the purposes of instruction and testing. Cumming writes that: "systematic modes of analyzing students' written texts are needed because the rating scales typically used to evaluate students' writing in a second language are simply too imprecise, or lack the theoretical rigor or validation, to be able to provide useful indicators of students' achievement" (p. 65). The article provides numerous up-to-date references to analyses of students' texts in specific genres.

Hamp-Lyons, L. (1991). Scoring procedures for ESL contexts. In L. Hamp-Lyons (Ed.), Assessing second language writing in academic contexts (pp. 241-276). Norwood, NJ: Ablex.

Appearing together with different other major articles on ESL writing assessment, this paper sets ESL writing in its specific before proceeding to review the most commonly used scoring procedures in testing writing. The article pertinently argues that it is important to have an appropriate method for the assessment of writing if one is to tap the full potential of writing instruction. Yet, this review of widespread scoring practices in writing suggests that many important discoursal features of texts throughout genres are hardly covered by these practices. The paper is recommended reading for anyone interested in ESL/EFL writing.

Kroll, B. (1998). Assessing writing abilities. Annual Review of Applied Linguistics, $18,219-240$.

The chapter provides a review of issues in second-language writing assessment in the past couple of decades. Critical variables present in writing assessment are identified as the writer, the task, the written product, the reader/scorer, and the scoring procedures. The article acknowledges that "a number of product studies have focused on specific rhetorical features identifiable in essays written for exams" (p. 224). Yet, the article maintains that there is too much variation in products across genres and that there are too many genres to consider for us to be able to benefit from such text studies. The author admits, however, that "the field of contrastive rhetoric. . .has helped to illuminate the fact that the particular ways in which texts are deemed to be appropriate and successful in achieving their rhetorical goals are at least somewhat culturally determined" (p. 225). 


\section{OTHER REFERENCES}

Alderson, C., Clapham, C., \& Wall, D. (1995). Language test construction and evaluation. Cambridge, UK: Cambridge University Press.

Bachman, L. F., \& Palmer, A. S. (1996). Language testing in practice: Designing and developing useful language tests. Oxford, UK: Oxford University Press.

Canale, M. (1983). From communicative competence to communicative language pedagogy. In J. C. Richards \& R. Schmidt (Eds.), Language and communication (pp. 2-27). London, UK: Longman.

Canale, M., \& Swain, M. (1980). Theoretical bases of communicative approaches to second language teaching and testing. Applied Linguistics, 1, 1-47.

Connor, U. (1990). Discourse analysis and writing/reading instruction. Annual Review of Applied Linguistics, 11,164-180.

Connor. U. (1994). Assessing writing proficiency. In E. M. White (Ed.), Teaching and assessing writing (pp. 150-170). San Francisco, CA: Jossey-Bass.

Connor, U. (1996). Contrastive rhetoric: Cross-cultural aspects of secondlanguage writing. Cambridge, UK: Cambridge University Press.

Connor, U., \& Lauer, J. (1988). Writing across languages and cultures. In A. C. Purves (Ed.), Cross-cultural variation in persuasive student writing (pp. 138-159). Newbury Park, CA: Sage.

Crismore, A. R., Markkanen, R., \& Steffensen, M. S. (1993). Metadiscourse in persuasive writing: A study of texts written by American and Finnish university students. Written Communication, 10, 39-71.

Educational Testing Service. (1989). Test of Written English Scoring Guidelines. Princeton, NJ: Author.

Hamp-Lyons, L. (Ed.). (1991). Assessing second language writing in academic contexts. Norwood, NJ: Ablex.

Jacobs, H., Zingraf, S. A., Wormuth, D. R., Hartfiel, V. F., \& Hughey, J. B. (1981). Testing ESL composition: A practical approach. Rowley, MA: Newbury House.

Kinneavy, J. L. (1971). A theory of discourse. Englewood Cliffs, NJ: Prentice Hall.

Lloyd-Jones, R. (1977). Primary trait scoring of writing. In C. R. Cooper \& L. Odell (Eds.), Evaluating writing: Describing, measuring, judging (pp. 33-66). Urbana, IL: National Council of Teachers of English.

Martin, J. R., \& Rothery, J. (1986). What a functional approach can show teachers. In B. Couture (Ed.), Functional approaches to writing: Research perspectives (pp. 789-808). Norwood, NJ: Ablex.

Purves, A. C. (1988). Introduction. In A. C. Purves (Ed.), Writing across languages and cultures: Issues in contrastive rhetoric (pp. 9-21). Newbury Park, CA: Sage. 
278 ULLA CONNOR AND AYMÉROU MBAYE

Schneider, M., \& Connor, U. (1991). Analyzing topical structure in ESL essays: Not all topics are equal. Studies in Second Language Acquisition, 12, 411-427.

Toulmin, S. (1958). The uses of argument. Cambridge, UK: Cambridge University Press.

Vande Kopple, W. J. (1985). Some exploratory discourse on metadiscourse. College Composition and Communication, 36, 82-93.

Weir, C. (1993). Understanding and developing language tests. New York: Phoenix.

White, E. (1985). Teaching and assessing writing. San Francisco, CA: JosseyBass.

Yancey, K. B., \& Huot, B. (1997). Assessing writing across the curriculum: Diverse approaches and practices. Greenwich, CT: Ablex. 
Reproduced with permission of the copyright owner. Further reproduction prohibited without permission. 